\title{
L-Band Polarimetric SAR Signatures of Lava Flows in the Northern Volcanic Zone, Iceland
}

\section{Dierking, Wolfgang; Haack, Henning}

\section{Published in:}

Geoscience and Remote Sensing Symposium Proceedings, 1998. IGARSS '98. 1998 IEEE International

Link to article, DOI:

10.1109/IGARSS.1998.691402

Publication date:

1998

Document Version

Publisher's PDF, also known as Version of record

Link back to DTU Orbit

Citation (APA):

Dierking, W., \& Haack, H. (1998). L-Band Polarimetric SAR Signatures of Lava Flows in the Northern Volcanic Zone, Iceland. In Geoscience and Remote Sensing Symposium Proceedings, 1998. IGARSS '98. 1998 IEEE International (Vol. 3, pp. 1339-1341). IEEE. https://doi.org/10.1109/IGARSS.1998.691402

\section{General rights}

Copyright and moral rights for the publications made accessible in the public portal are retained by the authors and/or other copyright owners and it is a condition of accessing publications that users recognise and abide by the legal requirements associated with these rights.

- Users may download and print one copy of any publication from the public portal for the purpose of private study or research.

- You may not further distribute the material or use it for any profit-making activity or commercial gain

- You may freely distribute the URL identifying the publication in the public portal 


\title{
L-Band Polarimetric SAR-Signatures of Lava Flows in the Northern Volcanic Zone, Iceland
}

\author{
Wolfgang Dierking and Henning Haack \\ Danish Center for Remote Sensing \\ Technical University of Denmark, Bldg. 348 \\ DK-2800 Lyngby, Denmark \\ Fax: +45-4593-1634, E-mail: wd@emi.dtu.dk, hh@emi.dtu.dk
}

\begin{abstract}
Studies of radar scattering signatures typical for lava surfaces are needed in order to interprete SAR images of volcanic terrain on the Earth and on other planets, and to establish a physical basis for the choice of optimal radar configurations for geological mapping. We focus on a study of polarimetric L-band radar signatures observed over different lava flows located in the Northern Volcanic Zone in Iceland. Intensity images with a high spatial resolution are well suited for geological interpretation, both in the discrimination of lava flows from the surrounding terrain and in the recognition of different morphologic types within a flow. The largest contrasts are observed at cross-polarization. The phase difference between the VV-and HH-channels may provide information about a vegetation cover on the lava. The radar signal scattered from the flows is dominated by surface scattering contributions with a comparatively large fraction of multiple scattering. Other scattering mechanisms can not be recognized.
\end{abstract}

\section{INTRODUCTION}

In the classification of lava types, the lava surface characteristics are important. Synthetic aperture radar (SAR) can be employed in separating lava flows from other terrain types and in the discrimination of different units within one flow since the radar is sensitive to surface roughness and bulk dielectric properties. The discrimination performance depends on the SAR parameters, that is on frequency, polarization, incidence angle, and spatial resolution. Recent investigations indicate that $\mathrm{L}$-band crosspolarized data acquired at larger incidence angles seem to be optimal for geologic interpretation [1].

In August 1997, the Danish airborne imaging radar EMISAR acquired fully polarimetric L-band data over a 150 by $50 \mathrm{~km}$ strip in the Northern Volcanic Zone, Iceland. The spatial resolution of the analysed images is 10 by $10 \mathrm{~m}$, the incidence angle varies between 35 and $67 \mathrm{deg}$ across the swath width. The investigated area encompasses lava flows of different ages and morphologies in the region North-East of Mývatn, Iceland, including the Krafla area and the postglacial lava fields covering the area between Gæsafjöll

This work was sponsored by the Danish National Research Foundation and the northern coastline. The objective of this study is to relate variations in the scattering signatures to geological characteristics of lava flows and to specify the contribution of different radar scattering mechanisms.

\section{GENERAL DESCRIPTION OF OBSERVED LAVA FLOW SIGNATURES}

Three-layer images in RGB-mode, combined from the backscattered intensities at VV-, HH-, and HV polarizations, reveal a close though not perfect correlation with geological maps. The younger and rougher lava flows can be identified easily in the images because of the comparatively large backscattered intensity, in particular at cross-polarization (HV). We used EMISAR covariance matrix data to calculate different polarimetric parameters on a pixel-by-pixel basis and depicted each parameter as an image. Although the images of the polarimetric parameters are noisy (each pixel in an EMISAR covariance matrix scene corresponds to 4-7 independent looks, dependent on range), the rougher lava flows differ clearly from the surrounding terrain in their depolarization ratio $\left[2 \sigma_{\mathrm{HV}}^{0} /\left(\sigma_{\mathrm{VV}}^{0}+\sigma_{\mathrm{HH}}^{0}\right)\right.$, where $\sigma_{\mathrm{pq}}^{0}$ is the backscattering coefficient at polarization $p q$ ] and, although less distinct, in their phase difference between the $\mathrm{HH}$ - and the VV-channel. The rather large backscattering coefficients at crosspolarization indicate that the contribution of multiple scattering to the received signal is significant. The observed contrast in the phase difference between lava flows and the surrounding area may be related to differences in the vegetation cover (on the young lava flows, there is no vegetation at all). The copolarization ratio, $\sigma_{\mathrm{Vv}}^{0} / \sigma_{\mathrm{HH}}^{0}$, which is close to one for rough lava flows is less suited for separating lava from the surrounding terrain, since in several cases the flow outlines cannot be identified. For investigations of different lava units within a flow, however, the copolarization ratio provides important information about the roughness of the lava surface. The correlation coefficient between the HH- and VV-channel seems to be of less practical value, since it neither allows a separation of lava from the surrounding terrain in most of the observed cases, nor helps to identify different flow units. However, the correlation coefficient is important in analysing the contribution of different scattering mechanisms to the received radar signal. 


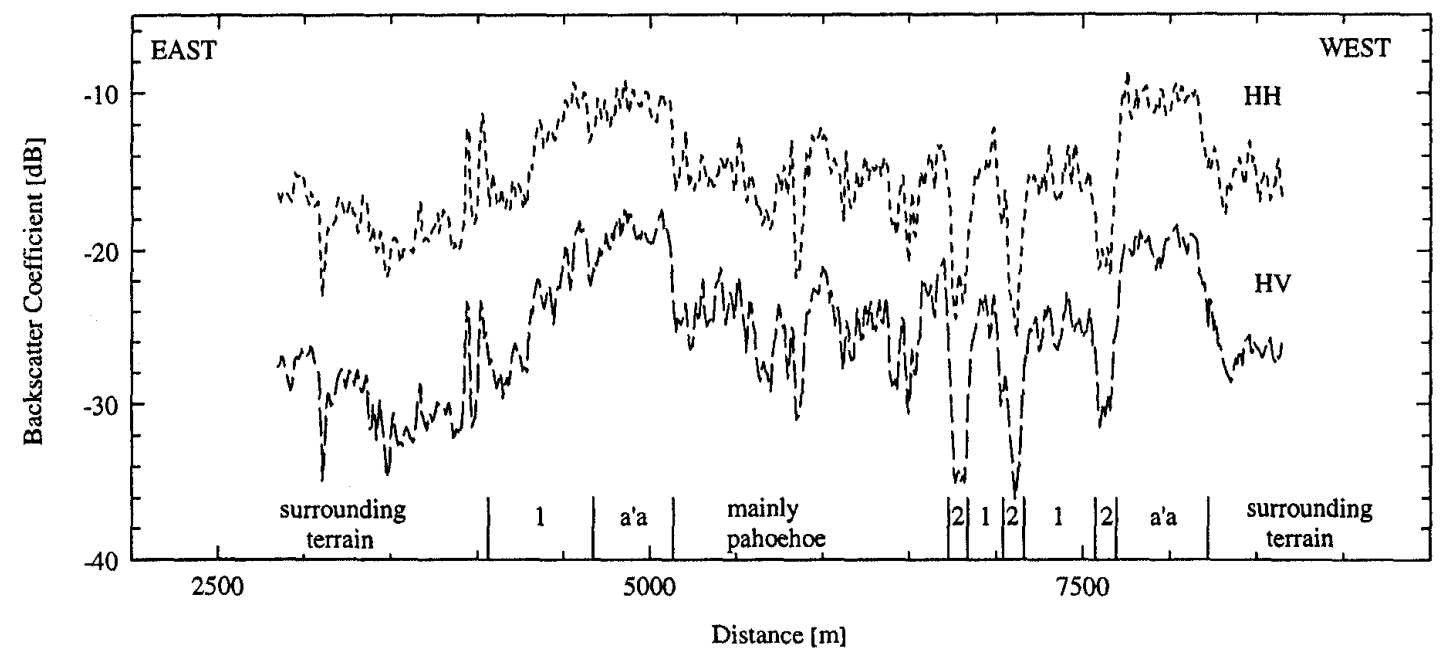

Figure 1. Average profile of backscattering coefficients across the Krafla Fire flows at $65^{\circ} 47^{\prime} \mathrm{N}(500 \mathrm{~m}$ south of the 1984 spatter cone). The average was taken from 10 adjacent pixels in the along flow direction. Units indicated by " 1 " are pahoehoe, and " 2 " is smooth pahoehoe.

Table 1: Positions of selected lava flows

\begin{tabular}{|c|c|c|}
\hline Flow & Center Coordinates & Remarks \\
\hline B & $65^{\circ} 38^{\prime} \mathrm{N} 17^{\circ} 06^{\prime} \mathrm{E}$ & a'a with birch bush cover $^{\prime}$ \\
\hline $\mathrm{C}$ & $65^{\circ} 36^{\prime} \mathrm{N} 17^{\circ} 20^{\prime} \mathrm{E}$ & grass covered a'a \\
\hline $\mathrm{D}$ & $65^{\circ} 45^{\prime} \mathrm{N} 17^{\circ} 10^{\prime} \mathrm{E}$ & Krafla Fire flow \\
\hline $\mathrm{I}$ & $65^{\circ} 18^{\prime} \mathrm{N} 17^{\circ} 35^{\prime} \mathrm{E}$ & a'a, no vegetation \\
\hline $\mathrm{J}$ & $65^{\circ} 27^{\prime} \mathrm{N} 17^{\circ} 40^{\prime} \mathrm{E}$ & mainly a'a \\
\hline $\mathrm{K}$ & $65^{\circ} 28^{\prime} \mathrm{N} 17^{\circ} 40^{\prime} \mathrm{E}$ & mainly a'a \\
\hline
\end{tabular}

Fig. 1 shows an example of backscatter variation across a lava flow with different lava facies (units). The classification is based on the work by [2] and was carried out through visual inspection of an EMISAR RGB-intensity image. The very rough a'a lava reveals large backscattering coefficients whereas the backscattered intensity from smooth pahoehoe sheets is rather low. In the images of the different polarimetric parameters the small areas of smooth pahoehoe can only be clearly distinguished in the depolarization ratio. This shows that intensity images of the HV-channel or of a combination of channels HV-HH-VV are most useful for geological interpretation.

In Fig. 2, variations of the HH- and HV-polarized backscattering coefficients $\sigma_{\mathrm{HH}}^{0}$ and $\sigma_{\mathrm{HV}}^{0}$ within single lava flows are shown. The selected lava flows appear visually inhomogeneous in the RGB-intensity images (positions of the flows are listed in Table 1). Each data point corresponds to the average value of a 150 by $150 \mathrm{~m}$ window (i. e. 225 pixels). The expected statistical error of $\sigma^{0}$ due to fading is less than $0.15 \mathrm{~dB}$. However, the observed standard deviation of $\sigma_{\mathrm{HH}}$ within a window varies between $1 \mathrm{~dB}$ and $2.6 \mathrm{~dB}$, and the corresponding values for $\sigma_{\mathrm{HV}}^{0}$ are $1 \mathrm{~dB}$ and $3.7 \mathrm{~dB}$. This means that the scattering characteristics are rather variable due to changes in the lava surface properties within an

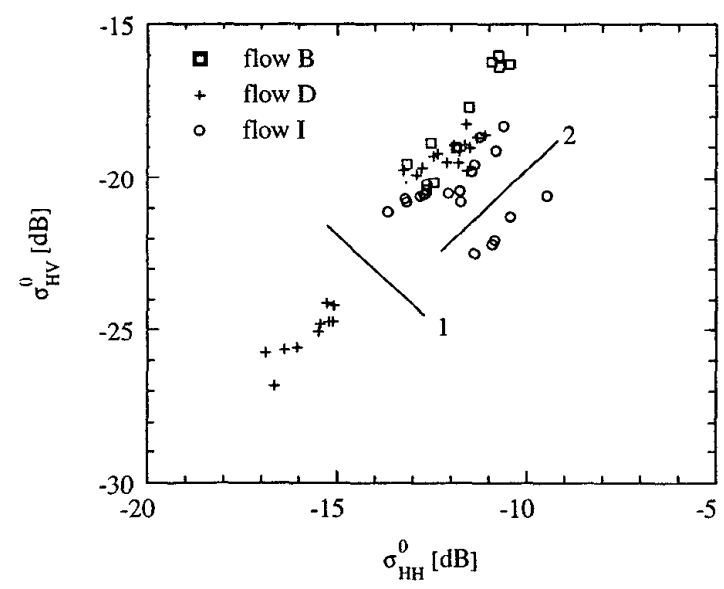

Figure 2. Variation of backscatter coefficients (HH- and HVpolarization) within selected flows. Lines indicate separation of different units within flow D (1) and I (2). 


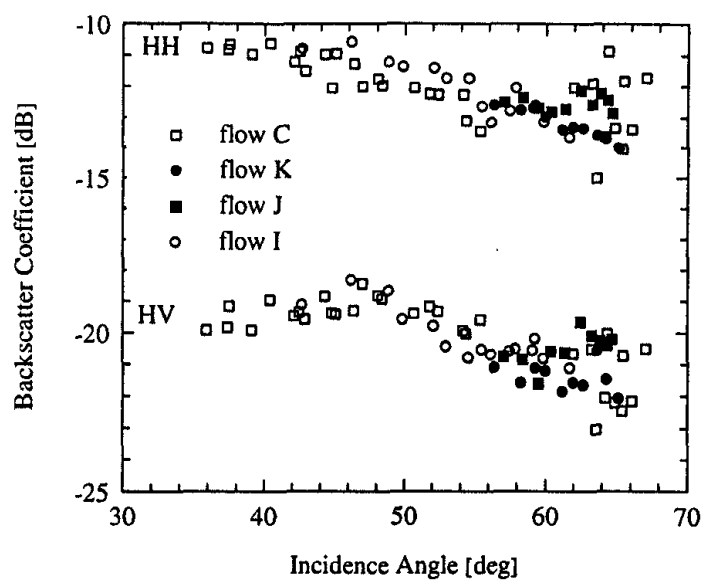

Figure 3. Backscatter coefficients at $\mathrm{HH}-$ and $\mathrm{HV}-$ polarization for different lava flows as a function of incidence angle. Each data mark was obtained from a window of 15 by 15 pixels. The statistical fluctuations of each value are between 1 and more than $3 \mathrm{~dB}$.

area corresponding to the window size. Taking these fluctuations into account, flow D and to some extent flow I are the only flows showing a clear separation between different units (indicated by lines 1 and 2 in Fig. 2). The observed differences between units cannot be explained by variations in the incidence angle. This indicates that an automated classification, based on averages over many pixels, may be possible in some cases. In comparison to aerial photography we noted that even small and less distinct units which may be hardly detectable in an automated classification can be visually distinguished in the RGBintensity images with $10 \mathrm{~m}$ spatial resolution.

\section{SCATTERING MECHANISMS}

Several field measurements indicate that lava flow surfaces are fractal-like and can be described by a power law roughness spectrum of the form $S(\mathbf{k})=c /|\mathbf{k}|^{\gamma}$, where $S$ is the power spectral density, $\mathbf{k}$ is the spatial wavenumber, $\log _{10}(\mathrm{c})$ is the spectral offset, and $\gamma$ is the spectral slope [3]. For such surfaces, the curves of $\sigma^{0}$ as a function of incidence angle may in certain cases deviate significantly from the patterns observed for non-fractal surfaces [4]. Considering the statistical fluctuations for each data window and possible surface properties variations between different windows, the curves shown in Fig. 3 do not give a clear indication of such a deviating behaviour. The shape of the curves is typical for very rough surfaces. We used the decomposition technique

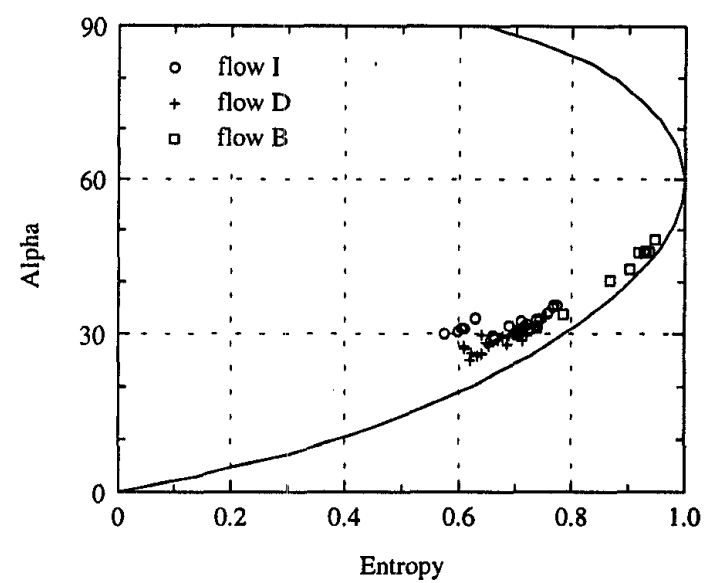

Figure 4. Decomposition according to [5] for selected lava flows.

proposed in [5] in order to analyze the dominant scattering contributions. The result is shown in Fig. 4. Almost all lava flows (only a few of them are represented in Fig. 4) reveal a "medium entropy" surface scattering behaviour which indicates a relatively high contribution of multiple scattering events. Only flow B is partly in the zone of "high entropy" scattering typical for vegetation with highly anisotropic scattering elements. This can be explained by the birch bush cover on flow $B$.

\section{REFERENCES}

[1] L. R. Gaddis, "Lava flow characterization at Pisgah volcanic field, California, with multiparameter imaging radar," Geol. Soc. Am. Bull., vol. 104, pp. 695-703, 1992.

[2] M. J. Rossi, "Morphology of the 1984 open-channel lava flow at Krafla volcano, northern Iceland," Geomorphology, vol. 20, pp. 95-112, 1997

[3] T. G. Farr, "Microtopographic evolution of lava flows at Cima Volcanic Field, Mojave Desert, California," J. Geophys. Res. Vol. 97(B11), pp. 15171-15179, 1992.

[4] O. I. Yordanov, and K. Ivanova, "Kirchhoff diffractals," J. Phys. A: Math. Gen., vol. 27, pp. 5979-5993, 1994.

[5] S. R. Cloude, and E. Pottier, "An entropy based classification scheme for land applications of polarimetric SAR," IEEE Trans. Geosci. Remote Sensing, vol. 35, pp. 68-78, 1997. 